\title{
Beta-elemene inhibits differentiated thyroid carcinoma metastasis by reducing cellular proliferation, metabolism and invasion ability
}

\author{
Lei Zhao", Jian Wei", Shiqi Wang, Tingting Lang, Xiaoguang Shi, Zhongyan Shan, Weiping Teng \\ Department of Endocrinology and Metabolism, Institute of Endocrinology, Liaoning Provincial Key Laboratory of Endocrine Diseases, The First \\ Affiliated Hospital of China Medical University, China Medical University, Shenyang, China \\ Contributions: (I) Conception and design: L Zhao, J Wei, X Shi; (II) Administrative support: X Shi, Z Shan, W Teng; (III) Provision of study materials \\ or patients: X Shi; (IV) Collection and assembly of data: S Wang, T Lang; (V) Data analysis and interpretation: L Zhao, J Wei; (VI) Manuscript \\ writing: All authors; (VII) Final approval of manuscript: All authors. \\ \#These authors contributed equally to this work. \\ Correspondence to: Xiaoguang Shi, MD. Department of Endocrinology and Metabolism, Institute of Endocrinology, Liaoning Provincial Key \\ Laboratory of Endocrine Diseases, The First Affiliated Hospital of China Medical University, China Medical University, No. 155, Nanjing Bei \\ Street, Shenyang, China. Email: xiaoguangshi_cmu@163.com.
}

Background: Accelerated glycolysis is a characteristic of carcinoma. The herb-derived compound, beta ( $\beta$ )-elemene, has shown promising anticancer effects against various tumors by inhibiting aerobic glycolysis. However, its activity against thyroid carcinoma and the mechanism is still unknown.

Methods: Differentiated thyroid carcinoma (DTC) cell lines, including papillary thyroid carcinoma (PTC) cell lines (IHH-4, TPC-1, K1), and follicular thyroid carcinoma (FTC) cell line (FTC133) were treated with different concentration of $\beta$-elemene. The viability of DTC cells was analyzed using the CCK8 method. Cell cycle and apoptosis analysis were performed by flow cytometry and western blotting. The cell invasion ability was evaluated in Transwell assays. Energy metabolism in living cells was measured using a Seahorse $\mathrm{XF}$ analyzer. The antitumor effects of $\beta$-elemene were analyzed in vivo in a nude mouse xenograft tumors model.

Results: CCK8 assays showed $\beta$-elemene significantly inhibited DTC cell proliferation in a dose- and time-dependent manner. $\beta$-elemene promoted cell apoptosis, with increased expression of cleaved caspase- 9 and decreased BCL-2 expression. Transwell assays showed that $\beta$-elemene significantly inhibited the invasion ability of DTC cells. $\beta$-elemene also reduced angiogenesis by decreasing VEGF expression in DTC cells. $\beta$-elemene reduces the basal oxygen consumption rate (OCR), extracellular acidification rate (ECAR), and maximal glycolytic capacity as well as maximal respiration and ATP production. Moreover, $\beta$-elemene inhibited tumor growth in a mouse xenograft model in vivo.

Conclusions: In this study, we have provided the first evidence of the antitumor effects of $\beta$-elemene, which was shown to inhibit cell proliferation, promote apoptosis, induce cell cycle arrest, inhibit cell invasion ability and reduce angiogenesis. Furthermore, we showed that $\beta$-elemene significantly inhibits the respiratory and glycolytic ability of human DTC cells. Thus, our findings show the potential of $\beta$-elemene as a novel treatment for DTC.

Keywords: Differentiated thyroid carcinoma (DTC); $\beta$-elemene; apoptosis; glycolysis

Submitted Mar 27, 2020. Accepted for publication Jul 25, 2020.

doi: $10.21037 /$ atm-20-4460

View this article at: http://dx.doi.org/10.21037/atm-20-4460 


\section{Introduction}

Thyroid carcinoma (TC) is one of the most common endocrine malignancies, and the incidence has increased worldwide more than any other cancer $(1,2)$. In the past 30 years, the incidence has increased by more than $300 \%$ in the United States (1). With histology, TC is classified into four major types: papillary, follicular, medullary, and anaplastic (3). Among all the TC subtypes, differentiated thyroid cancer (DTC), which includes the papillary and follicular types, accounts for more than $90 \%$ of cases (4). Following standard surgical treatment in conjunction with radioiodine ablation and TSH suppression therapy, the 5 -year disease-specific survival rate of TC is approximately 98\% (5). However, despite its positive prognosis, regional, and cervical lymph node recurrence occurs in up to $13 \%$ DTC patients (6), resulting in a significant challenge to the long-term survival of DTC patients.

Otto Warburg first reported aerobic glycolysis in the 1950s (7). More recently, the theory of the Warburg effect has been applied to cancer cell metabolism (8). Although oxidative phosphorylation produces ATP more efficiently, aerobic glycolysis produces ATP more rapidly, which suits the metabolic needs of rapidly proliferating cancer cells $(8,9)$. By this theory, DTC cells show higher rates of efficient glycolysis (10).

Elemene (1-methyl-1-vinyl-2,4-diisopropylcyclohexane) is a lipid-soluble anticancer drug extracted from the traditional Chinese medicinal herb Rhizoma zedoariae (11). The elemene extract comprises a mixture of beta $(\beta)$-, delta $(\delta)$-, and gamma $(\gamma)$-elemene, with $\beta$-elemene as the main component, accounting for $60-72 \%$ of the three isoforms (12). $\beta$-Elemene, the active component of elemene, is effective against various tumors, including liver, lung, and breast cancer (13-15); however, the underlying mechanism remains to be fully elucidated. One study indicated the anticancer effects of $\beta$-elemene combined with rapamycin (16). However, the influence of $\beta$-elemene alone on DTC cells and the underlying mechanism are unclear. In this study, we investigated the antitumor effect of $\beta$-elemene on human DTC cells. Our results showed that $\beta$-elemene inhibited cell proliferation, promoted apoptosis, and arrested cell cycle progression.

Furthermore, $\beta$-elemene inhibited DTC cell invasion ability and reduced angiogenesis. $\beta$-elemene also significantly inhibited the respiratory and glycolytic ability of human DTC cells, which could form the basis of the mechanism antitumor effect of $\beta$-elemene. Finally, the antitumor effect of $\beta$-elemene was confirmed in vivo in a mouse xenograft model.

We present the following article in accordance with the ARRIVE reporting checklist (available at http://dx.doi. org/10.21037/atm-20-4460).

\section{Methods}

\section{Cell culture}

Thyroid carcinoma cells were supported in Dulbecco's modified Eagle medium (DMEM) containing 10\% fetal bovine serum (FBS) and cultured at $37{ }^{\circ} \mathrm{C}$ in a humidified atmosphere containing $5 \% \mathrm{CO}_{2}$. Papillary thyroid carcinoma (PTC) cell lines (IHH-4, TPC-1, K1) and follicular thyroid carcinoma (FTC) cell line (FTC133) were incubated overnight and then exposed to $\beta$-elemene $(0,10$, $20,40,60,80,120$ and $160 \mu \mathrm{g} / \mathrm{mL}$ ) for 24,48 or 72 hours.

\section{Reagents and antibodies}

$\beta$-Elemene (98\% purity) was obtained from Yuanda Pharmaceuticals (Dalian, China). Propidium iodide (PI), RNase, and glycine were bought from Sigma-Aldrich (St. Louis, MO, USA). The primary antibodies against cyclinE, cyclinB1, CDK1, CDK2, CDK6, caspase-8, cleaved caspase-9, BCL-2, VEGF, and $\beta$-actin and the HRPconjugated goat anti-rabbit IgG secondary antibody was from Cell Signaling Technology (Beverly, MA, USA). The human DTC cell lines, IHH-4, TPC-1, K1, and FTC133, were obtained from the Health Science Research Resources Bank (Osaka, Japan). DMEM, FBS, and 0.25\% trypsinEDTA solution were bought from Gibco (Gaithersburg, MD, USA).

\section{Cell viability assay}

Cell viability or the effects of $\beta$-elemene on cell proliferation were measured using the CCK8 method. In brief, $4 \times 10^{3}$ cells/well (IHH-4, TPC-1, K1, and FTC133) were evenly distributed and cultured in 96-well plates overnight at $37{ }^{\circ} \mathrm{C}$ in a humidified atmosphere containing $5 \% \mathrm{CO}_{2}$. After that, the cells were incubated for another hour at $37^{\circ} \mathrm{C}$ with $10 \mu \mathrm{L} \mathrm{CCK} 8$. And the optical density of each well was measured at $450 \mathrm{~nm}$ with a microplate reader (Infinite ${ }^{\circledR} 200$ PRO, Tecan). 


\section{Cell cycle analysis by flow cytometry}

After treatment with various concentrations of $\beta$-elemene $(0,10,20,40,60,80,120$ and $160 \mu \mathrm{g} / \mathrm{mL})$ for 24,48 or 72 hours, the cells $\left(1 \times 10^{6}\right)$ were stained with PI following incubation with $0.2 \mathrm{mg} / \mathrm{mL}$ RNase for 30 minutes. Finally, flow cytometry analyzed the cells using a FACS Calibur (Becton-Dickinson, San Diego, CA, USA). Cell cycle phase distribution was analyzed with ModFit LT software (Verity Software House, USA).

\section{Analysis of apoptosis}

IHH-4, TPC-1, K1, and FTC133 cells were seeded at $1.5 \times 10^{5}$ cells/well in 6 -well plates, incubated overnight, and then exposed to $0,20,40$, or $60 \mu \mathrm{g} / \mathrm{mL}$ of $\beta$-elemene for 24 hours. Cells were collected and incubated with $1 \mu \mathrm{g} / \mathrm{mL}$ Annexin V-FITC (Becton-Dickinson) for 20 minutes in the dark. Finally, flow cytometry evaluated the samples, and the data were analyzed using FlowJo software.

\section{Transwell assay of cell invasion ability}

Transwell chambers were prepared by the addition of $40 \mu \mathrm{L}$ ECM Gel (dissolved in serum-free medium at 1:7.5) per well in the upper chamber. The plates were incubated at $37^{\circ} \mathrm{C}$ for 30 minutes to allow polymerization of the Matrigel. Cells treated with different concentrations of $\beta$-elemene $(0,20,40$, and $60 \mu \mathrm{g} / \mathrm{mL})$ for 24 hours were harvested, resuspended in serum-free DMEM medium, and the cell density was adjusted to $1.5 \times 10^{5} / \mathrm{mL}$. Cells $(200 \mu \mathrm{L})$ were then added to the Transwell upper chamber, while $500 \mu \mathrm{L}$ of medium containing $10 \%$ FBS was added to the lower chamber. The plates were incubated for 12 hours at $37^{\circ} \mathrm{C}$ in a humidified atmosphere holding $5 \% \mathrm{CO}_{2}$. After the Transwell chamber was removed, the cells were fixed with paraformaldehyde and stained with crystal violet. After observation under a Leica upright microscope, the Transwell chambers were photographed, and the numbers of cells in five randomly selected fields were view recorded.

\section{Western blot analysis}

IHH-4, TPC-1, K1 and FTC133 cells were treated with different concentrations $(0,20,40$ or $60 \mu \mathrm{g} / \mathrm{mL})$ of $\beta$-elemene for 24 hours. The cells were washed twice with ice-cold PBS and harvested on ice. The total protein content was quantified using the Lowry method. Cell lysate proteins $(50 \mu \mathrm{g})$ were separated by sodium dodecyl sulfatepolyacrylamide gel electrophoresis and electrophoretically transferred to nitrocellulose membranes (Immobilon-P; Millipore, USA). The membranes were blocked with $5 \%$ skimmed milk in TBS-T buffer $[10 \mathrm{mmol} / \mathrm{L}$ Tris $(\mathrm{pH}$ 7.4), $150 \mathrm{mmol} / \mathrm{L} \mathrm{NaCl}$ and $0.1 \%$ Tween-20] at room temperature for 2 hours and incubated overnight at $4{ }^{\circ} \mathrm{C}$ with the indicated primary antibodies against cyclinE, cyclinB1, CDK1, CDK2, CDK6, caspase-8, cleaved caspase-9, BCL-2 or VEGF. The membranes were then incubated with HRP-conjugated secondary antibodies for $2 \mathrm{~h}$ at room temperature. After extensive washing with TBS-T buffer, the proteins were visualized with an enhanced chemiluminescence reagent. The images were analyzed using NIH Image J software.

\section{The respiratory and glycolytic ability of living cells}

The XFe 96 Extracellular Flux analyzer (Seahorse Biosciences, Billerica, MA, USA) measures real-time uptake and release of metabolic end products. Each XFe 96-assay well holds a disposable sensor cartridge, embedded with 96 pairs of fluorescent biosensors (oxygen and $\mathrm{pH}$ ), coupled to fiber-optic waveguides. This technology was used to measure oxygen consumption rate (OCR) and extracellular acidification rate (ECAR) in cells treated with $\beta$-elemene. Mitochondrial respiratory ability and glycolytic ability of these cells were investigated using commercial kits (Seahorse Biosciences) according to the manufacturer's instructions.

\section{In vivo experiments}

Twelve nude mice (aged 4 weeks, $18 \pm 2 \mathrm{~g}$ ) were obtained from Shanghai SLAC Laboratory Animal Co. Ltd. (Shanghai, China). All animal experiments were approved by the Animal Ethics Committee of China Medical University. All procedures were performed following the Guide for the Care and Use of Laboratory Animals and complied with institutional ethical guidelines. Mice were injected subcutaneously with $5 \times 10^{6} \mathrm{IHH}-4$ cells and then randomized into two equal groups $(n=6)$ before drug treatment was started. $\beta$-Elemene was formulated as emulsions and injected intraperitoneally. One group was treated with $\beta$-elemene emulsion $(50 \mathrm{mg} / \mathrm{kg})$ every three days for 15 days, while the control group was treated with blank emulsions alone as the vehicle. Tumors were measured using a ruler by the same person weekly posttreatment. Tumor size was determined by measurement 

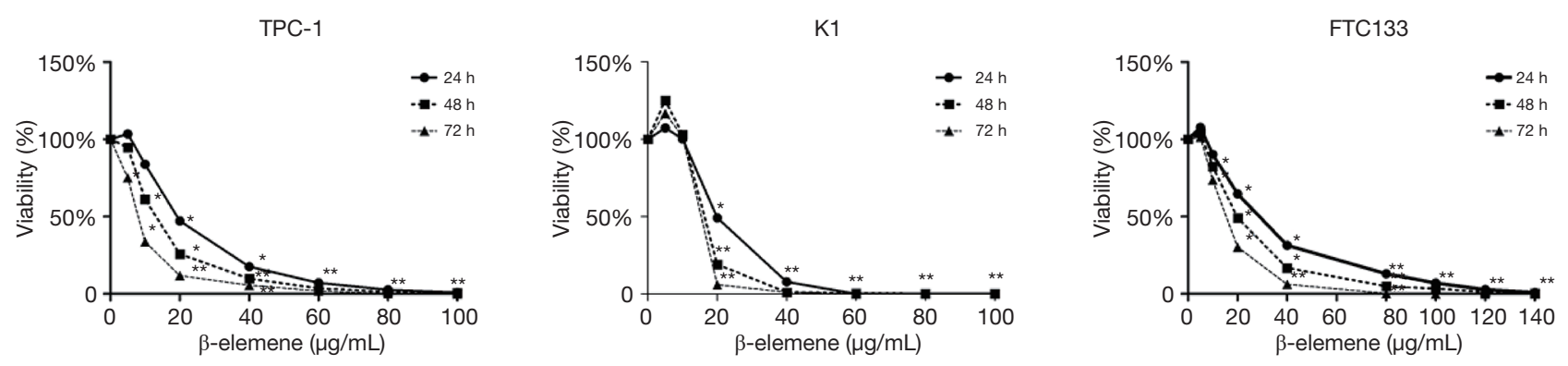

Figure $1 \beta$-Elemene inhibited the growth of human DTC cell lines in a dose- and time- dependent. *, compared to control, $\mathrm{P}<0.05$; **, compared to control, $\mathrm{P}<0.001$. DTC, differentiated thyroid carcinoma.

of the maximum and minimum superficial diameters every other day. Tumor volumes were calculated according to the formula: $\mathrm{V}=1 / 2 \mathrm{ab}^{2}$, where $\mathrm{a}$ and $\mathrm{b}$ denote the maximum and minimum superficial diameter, respectively.

\section{Statistical analysis}

All values were expressed as the mean \pm standard deviation (SD) of at least three independent experiments. Intergroup differences were evaluated using the Student's $t$-test and ANOVA. $\mathrm{P}<0.05$ was considered to show statistical significance.

\section{Results}

\section{Inbibitory effects of $\beta$-elemene on the growth of human DTC cell lines}

To evaluate the antitumor effects of $\beta$-elemene on DTC cells, we investigated the ability of $\beta$-elemene to inhibit cell viability in vitro using the CCK8-based colorimetric assay. Treatment of DTC cell lines with $\beta$-elemene at concentrations ranging from 10 to $160 \mu \mathrm{g} / \mathrm{mL}$ for 24,48 , and 72 hours showed that cell growth was inhibited in a dose and time-dependent manner (Figure 1). The halfmaximal inhibitory concentrations $\left(\mathrm{IC}_{50}\right)$ of $\beta$-elemene on IHH-4 cell growth were $42.2 \pm 1.53,36.6 \pm 0.85$, and $39.1 \pm 1.26 \mu \mathrm{g} / \mathrm{mL}$ at 24,48 , and 72 hours, respectively. The $\mathrm{IC}_{50}$ values of $\beta$-elemene on TPC-1, K1, and FTC133 cells showed a similar trend.

\section{Effects of $\beta$-elemene on cell cycle progression of human DTC cell lines}

After exposure to $\beta$-elemene, the populations of IHH-4, TPC-1, and FTC133 cells in the G1 phase were increased in a concentration-dependent manner, indicating that $\beta$-elemene induced cell cycle arrest in the G1 phase (Figure 2A). Following exposure to $\beta$-elemene, the populations of $\mathrm{K} 1$ in the $\mathrm{G} 2$ phase were increased, showing that $\beta$-elemene induced cell cycle arrest in the G2 phase. We measured the expression levels of cyclinE, CDK2, and CDK6 by western blot in the IHH-4, TPC-1, K1, and FTC133 cells treated with $\beta$-elemene (Figure $2 B, C$ ). In IHH-4, TPC-1, and FTC133 cells, the levels of cyclinE, CDK2, and CDK6 decreased in a dose-dependent manner after exposure to different concentrations of $\beta$-elemene. Meanwhile, the expression levels of cyclinB1 and CDK1 decreased in $\mathrm{K} 1$ cells.

\section{Effects of $\beta$-elemene on apoptosis in human DTC cell lines}

$\beta$-Elemene induced apoptosis in IHH-4, TPC-1, K1, and FTC133 cells in a dose-dependent manner (Figure $3 A$ ). Caspase- 8 and caspase- 9 are markers of the extrinsic pathway and intrinsic pathways of apoptosis, respectively, while BCL-2 plays a critical role in the inhibition of cell apoptosis $(17,18)$. As shown in Figure 3B,C, cleaved caspase-9 expression increased, and BCL-2 expression decreased in IHH-4, K1, and FTC133 cells following $\beta$-elemene treatment, while there was no significant change in caspase- 8 protein expression. However, in the TPC-1 cell line, $\beta$-elemene treatment increased the expression of caspase- 8 and cleaved caspase-9, while BCL-2 expression was reduced.

\section{Effects of $\beta$-elemene on the invasiveness of human DTC cell lines}

As shown in Figure $4 A$, $\beta$-elemene $(0,10,20$, and $40 \mu \mathrm{g} / \mathrm{mL})$ significantly inhibited numbers of IHH-4, TPC-1, K1, and 


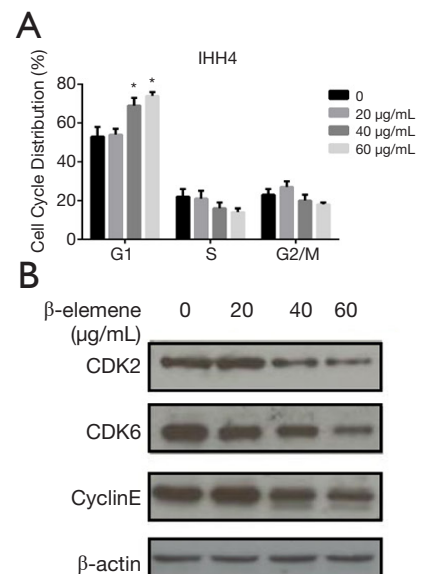

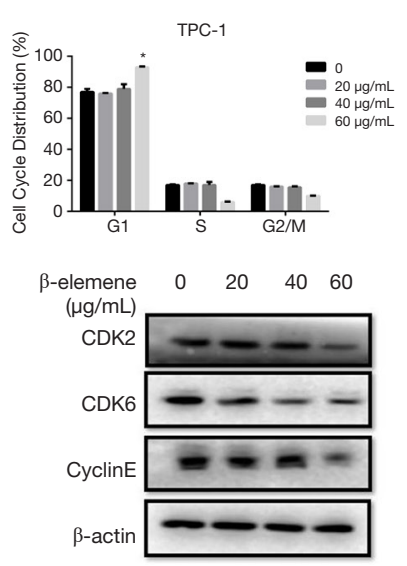

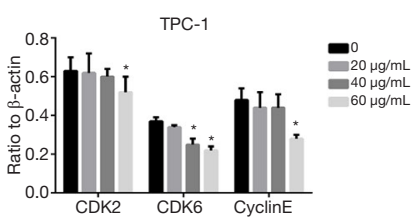

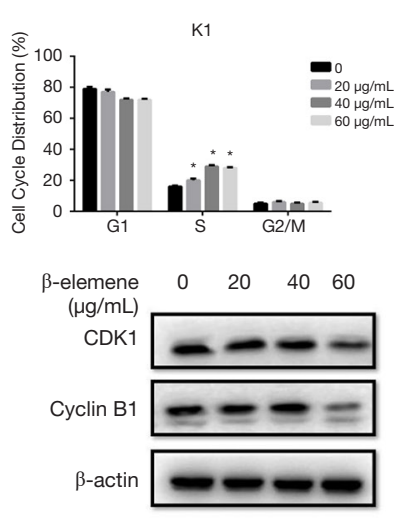
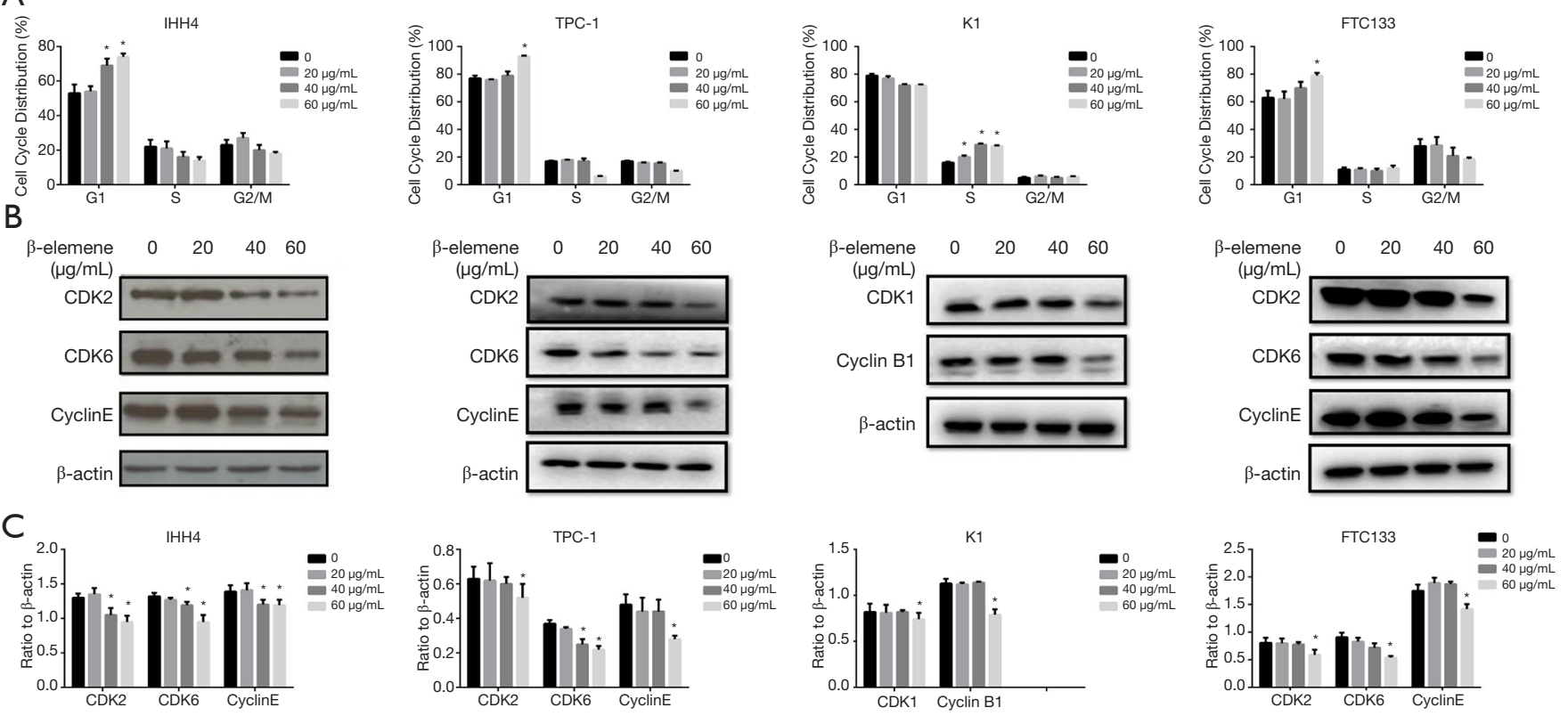

Figure $2 \beta$-Elemene induced cell cycle arrest in the G1 or G2 phase and decreased the expression of cell cycle-associated proteins in human DTC cell lines. (A) The IHH-4, TPC-1, and FTC133 cell populations in the G1 phase of the cell cycle were increased in a concentrationdependent manner after treatment with $\beta$-elemene by using flow cytometric analysis. The K1 cell population in the G2 phase of the cell cycle was increased by using flow cytometric analysis. (B,C) Based on flow cytometry results, the expression of cell cycle-associated proteins were measured. Expression of cyclinE, CDK2, and CDK6 decreased in a dose-dependent manner after exposure of IHH-4, TPC-1, and FTC133 cells to different concentrations of $\beta$-elemene. Expression levels of cyclinB1 and CDK1 decreased in K1 cells. *, compared to control, $\mathrm{P}<0.05$. DTC, differentiated thyroid carcinoma.

FTC133 cells that migrated through the Matrigel layer in Transwell assays in a dose-dependent manner (all $\mathrm{P}<0.05$ ).

\section{The effect of $\beta$-elemene on the expression of VEGF in buman DTC cell lines}

As shown in Figure 4B, C, VEGF expression in IHH-4, TPC-1, K1, and FTC133 cells decreased after treated with different concentrations of $\beta$-elemene in a dose-dependent manner.

\section{Effects of $\beta$-elemene on the respiratory and glycolytic ability of human DTC cells}

Energy metabolism is crucial for cell proliferation and pathobiological behavior. We hypothesized that $\beta$-elemene alters energy metabolism in DTC cells, and these changes are manifested as reduced proliferation and increased apoptosis. To test this hypothesis, we measure the mitochondrial respiratory capacity and glycolytic capacity of DTC cells pretreated with different concentrations of $\beta$-elemene $(0,5,10,20,30,40$, and $50 \mu \mathrm{g} / \mathrm{mL})$ using an XFe 96 Extracellular Flux analyzers. After treatment with $\beta$-elemene at $20 \mu \mathrm{g} / \mathrm{mL}$, the basal ECAR and maximal glycolytic capacity of IHH4 cells were reduced, showing that $\beta$-elemene inhibits IHH4 cell glycolysis at this dose (Figure $5 A$ ). Interestingly, $\beta$-elemene treatment at $5 \mu \mathrm{g} / \mathrm{mL}$ also reduced the basal OCR, maximal respiration and ATP production of IHH4 cells, indicating that $\beta$-elemene inhibits mitochondrial aerobic respiration in $\mathrm{IHH} 4$ cell at this dose (Figure $5 A$ ). The results showed that $\beta$-elemene inhibited the mitochondrial respiratory ability and glycolytic ability of IHH4 cells in a dose-dependent manner. Comparable results were obtained in analyses of TPC-1 (Figure 5B), K1 (Figure 5C), and FTC133 (Figure 5D).

\section{Anti-growth effects of $\beta$-elemene on IHH-4 buman PTC cells in xenograft mice}

At 7 and 14 days after treatment with $\beta$-elemene or 


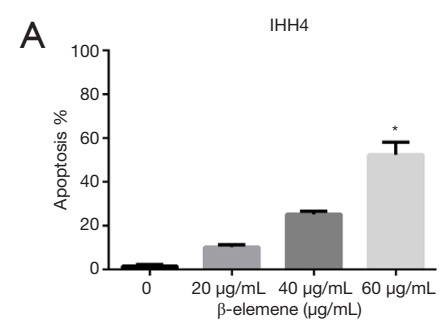

B

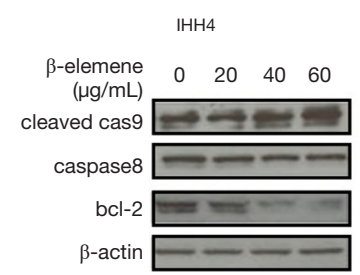

C

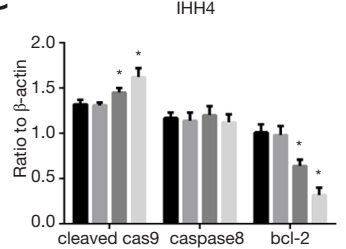

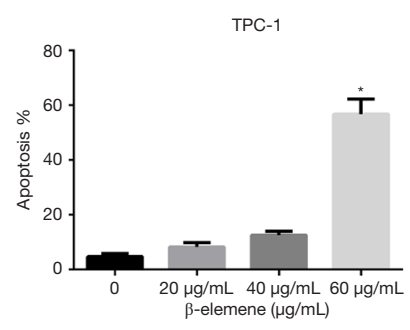

TPC-1

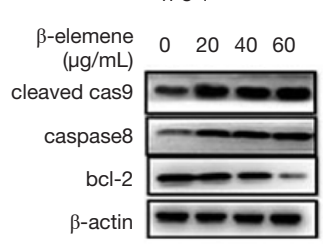

TPC-1

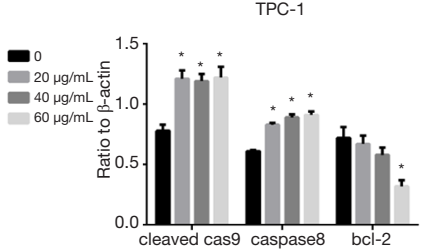

K1

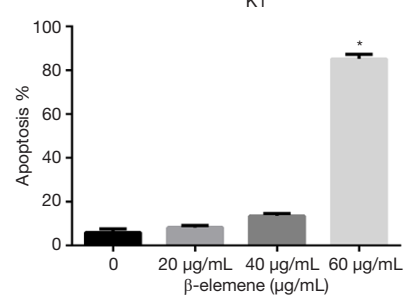

K1

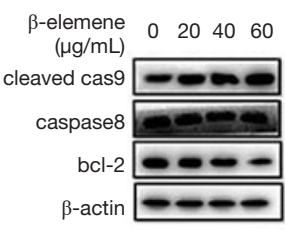

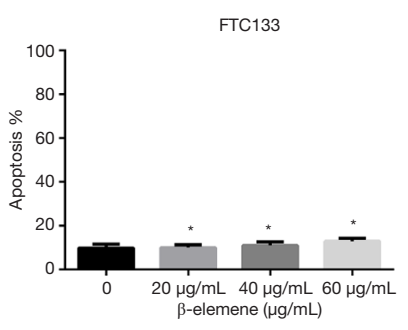

FTC133

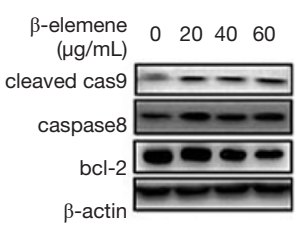

FTC133

Figure $3 \beta$-Elemene induced apoptosis and changed expression of apoptosis-associated proteins in human DTC cell lines. (A,B) $\beta$-Elemene induced apoptosis in DTC cells in a dose-dependent manner by using flow cytometric analysis. (C) In IHH-4, K1, and FTC133 cells, $\beta$-elemene reduced the expression of BCL-2 and increased the expression of cleaved caspase-9, but did not affect caspase-8 protein levels. In TPC-1 cells, $\beta$-elemene reduced BCL-2 expression and increased the expression of cleaved caspase-9 and caspase-8. *, compared to control, $\mathrm{P}<0.05$. DTC, differentiated thyroid carcinoma.

blank emulsions, tumor volumes in untreated mice were significantly larger than those in the drug-treated mice, which confirmed $\beta$-elemene inhibited the growth of IHH-4 cells in vivo. Representative images of a tumor mass from a mouse treated with either $\beta$-elemene or blank emulsion are shown in Figure 6.

\section{Discussion}

The rapidly increasing incidence of TC is a cause for concern in many countries $(19,20)$. Although most thyroid cancer patients have an excellent outcome, and welldifferentiated carcinoma is often curable by the combination of surgery and radioiodine ablation, approximately $10 \%$ of these patients lose the ability to respond to radioiodine therapy, leading to recurrent disease and death (21-23). Thus, new effective therapeutic strategies are urgently required in such cases of advanced differentiated thyroid carcinoma (DTC) (21).

Accelerated glycolysis is a characteristic of carcinoma $(22,23)$. Previous studies have shown a metabolic shift occurs in many tumors and correlates with negative prognoses (24-26). Our study showed that $\beta$-elemene significantly inhibited the respiratory and glycolytic ability of human DTC cells, with both basal ECAR and maximal glycolytic capacity reduced in a dose-dependent manner. These results show that $\beta$-elemene targets human DTC cell metabolism. However, to our prediction, $\beta$-elemene treatment did not result in the conversion of glycolysis to mitochondrial aerobic respiration. $\beta$-Elemene treatment reduced the basal OCR maximal respiration and ATP production of DTC cell lines, indicating that $B$-elemene inhibits mitochondrial aerobic respiration. This suppression of mitochondrial aerobic respiration was observed at concentrations of $\beta$-elemene as low as $5 \mu \mathrm{g} / \mathrm{mL}$, while a higher concentration $(20 \mu \mathrm{g} / \mathrm{mL})$ was required for suppression of glycolysis. Further studies must clarify the metabolism pathways influenced by the $\beta$-elemene treatment of DTC cells.

Rapid growth is a common feature of tumor cells. Thus, growth inhibition and cell cycle arrest are fundamental indexes of drug antitumor effects in vitro (27). In our study, we observed cell cycle arrest of IHH-4, TPC-1, and 

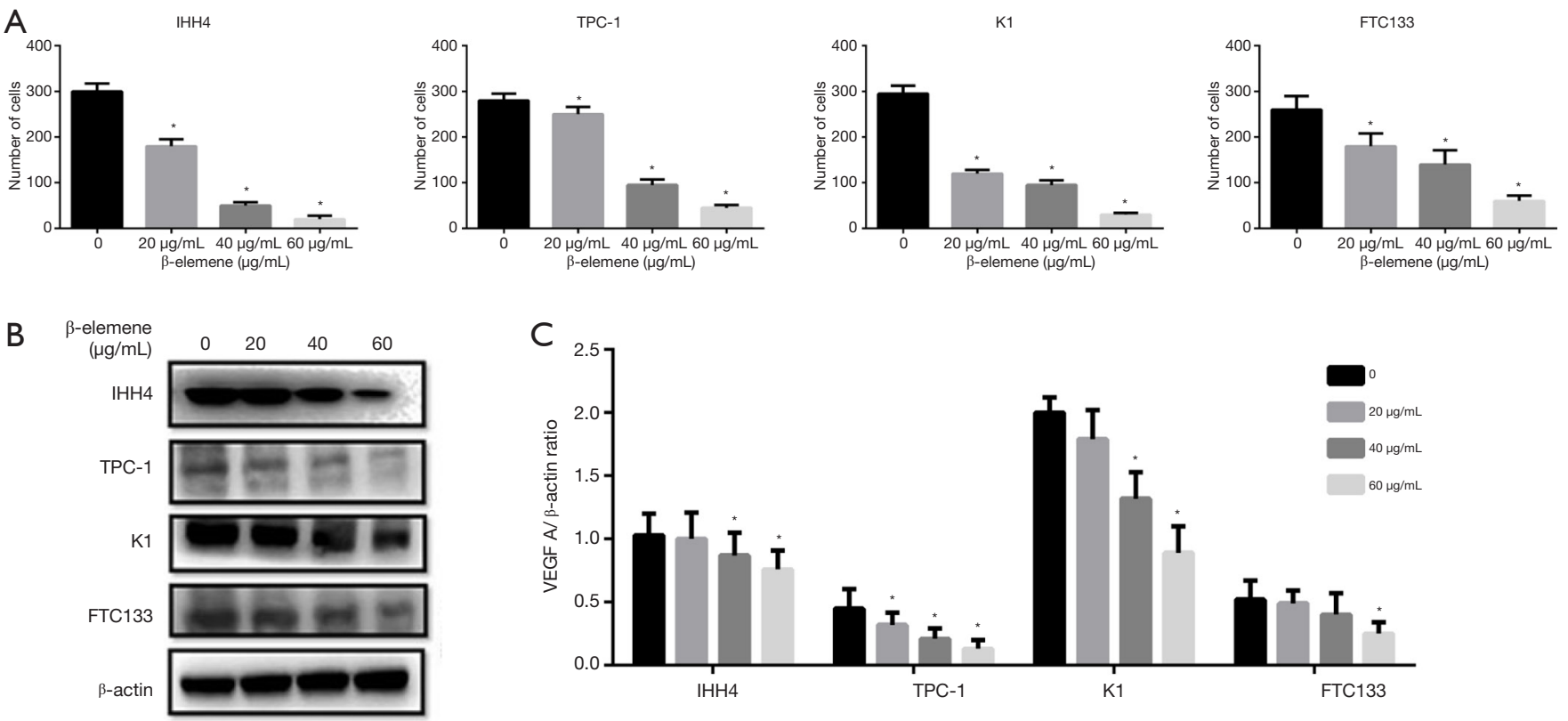

Figure $4 \beta$-Elemene inhibited cell invasiveness and decreased VEGF A protein expression in DTC cell lines. (A) $\beta$-elemene (0, 10, 20, and $40 \mu \mathrm{g} / \mathrm{mL}$ ) significantly inhibited numbers of IHH-4, TPC-1, K1, and FTC133 cells that migrated through the Matrigel layer in Transwell assays in a dose-dependent manner $(\mathrm{P}<0.05)$. (B,C) VEGF expression in IHH-4, TPC-1, K1, and FTC133 cells decreased treated with different concentrations $(0,10,20$, and $40 \mu \mathrm{g} / \mathrm{mL})$ of $\beta$-elemene $(\mathrm{P}<0.05) .{ }^{*}$, compared to control, $\mathrm{P}<0.05$. DTC, differentiated thyroid carcinoma.

FTC133 cells in the G1 phase following treatment with when treated with $\beta$-elemene. This effect was accompanied by decreased expression of cyclinE, CDK2, and CDK6, three proteins are known to regulate the G1 phase. Similarly, $\beta$-elemene treatment resulted in K1 cell cycle arrest in the G2 phase, combined with decreased expression of cyclinB1 and CDK1, proteins that regulate the G2 phase of the cell cycle. This phenomenon reflected the antitumor effects of $\beta$-elemene on human DTC cells in vitro in a timeand dose-dependent manner.

Bcl-2 family proteins, which are essential regulators of cell apoptosis (28), can be divided into subcategories of antiapoptotic proteins, including BCL-2, and pro-apoptotic proteins, including Bax. The ratio of anti-apoptotic proteins and pro-apoptotic protein defines the sensitivity of cells to apoptotic signals (29). Studies have shown $\beta$-elemene induces cell apoptosis via the mitochondrial caspasedependent pathway. In lung cancer and prostate cancer, $\beta$-elemene can reduce BCL-2 expression and increase the expression of cytochrome $\mathrm{C}, \mathrm{ADP}$ ribose polymerase (PARP), caspase 3, caspase 7, and caspase 9 (30). In our study, we found that $\beta$-elemene treatment of IHH-4, K1, and FTC133 cells reduced BCL-2 expression and increased cleaved caspase- 9 expression. These observations showed that $\beta$-elemene induces apoptosis in $\mathrm{IHH}-4, \mathrm{~K} 1$, and FTC133 cells via a caspase-9-dependent pathway. TPC-1 cells, $\beta$-elemene treatment reduced BCL-2 expression, while cleaved caspase- 9 and caspase- 8 expression were increased, indicating that apoptosis was induced not only via a caspase-9-dependent pathway, but also through a caspase8 -dependent pathway. Thus, our findings supply evidence that the anticancer actions of $\beta$-elemene are mediated by its ability to regulate cell cycle progression and apoptosis in DTC cells.

The invasiveness nature of tumor cells is the main reason for the failure of cancer treatment. At present, it is widely believed that the adhesion of cancer cells to surrounding tissues is a critical factor leading to the migration and invasion of tumor cells (31). Therefore, clarification of the effect of $\beta$-elemene on the invasive ability of DTC cells is of great significance in the elucidation of its anticancer mechanism. In this study, we found $\beta$-elemene inhibited the invasiveness of IHH-4, TPC-1, K1, and FTC133 cell lines, with amounts of cells passing through Matrigel decreasing 

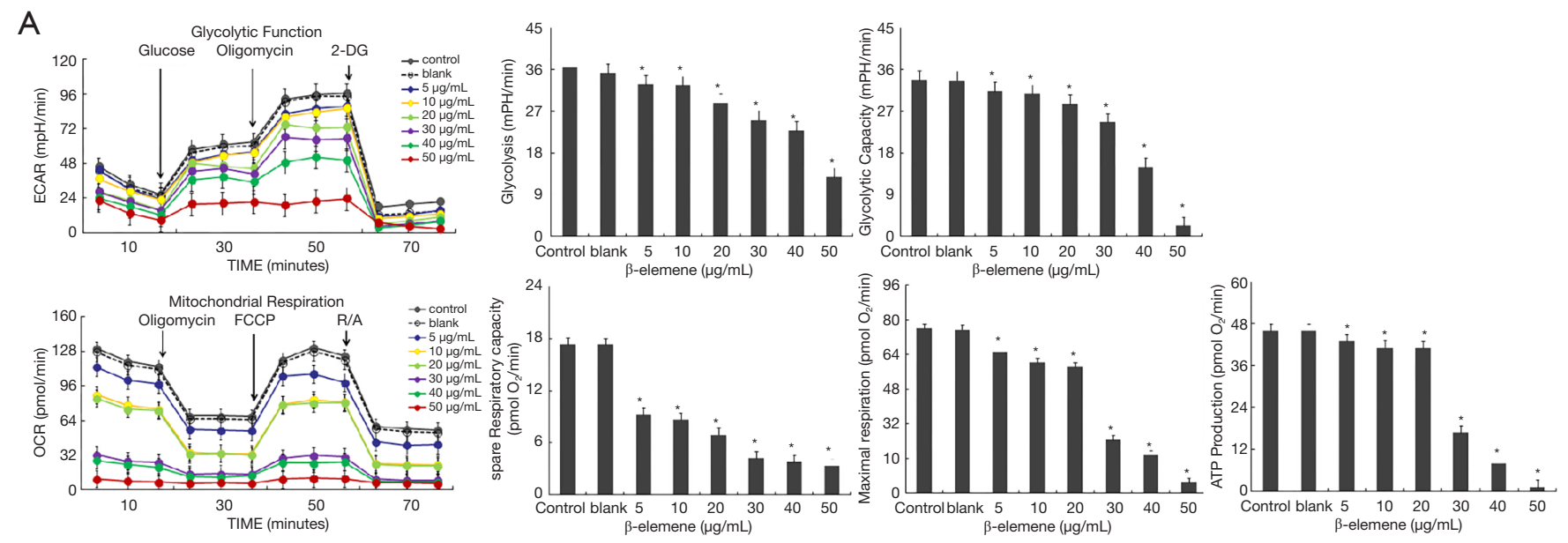

B
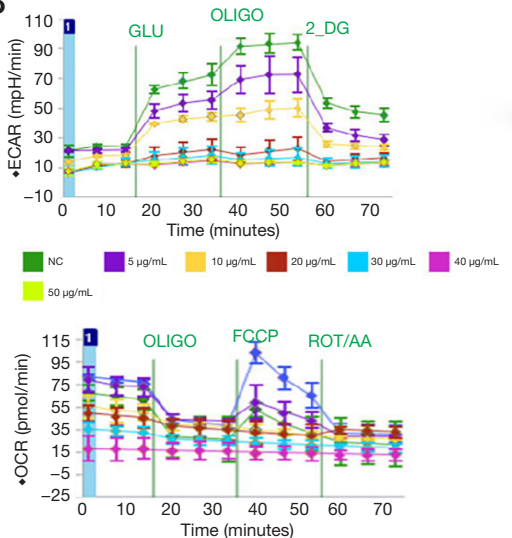

$\square \mathrm{NC} \quad \square=5 \mathrm{gg} / \mathrm{mL} \square 10 \mu \mathrm{g} / \mathrm{mL} \quad 20 \mu \mathrm{g} / \mathrm{mL}$ $\square 0 \mu \mathrm{g} / \mathrm{mL} \quad 40 \mu \mathrm{g} / \mathrm{mL} \quad 50 \mu \mathrm{g} / \mathrm{mL}$
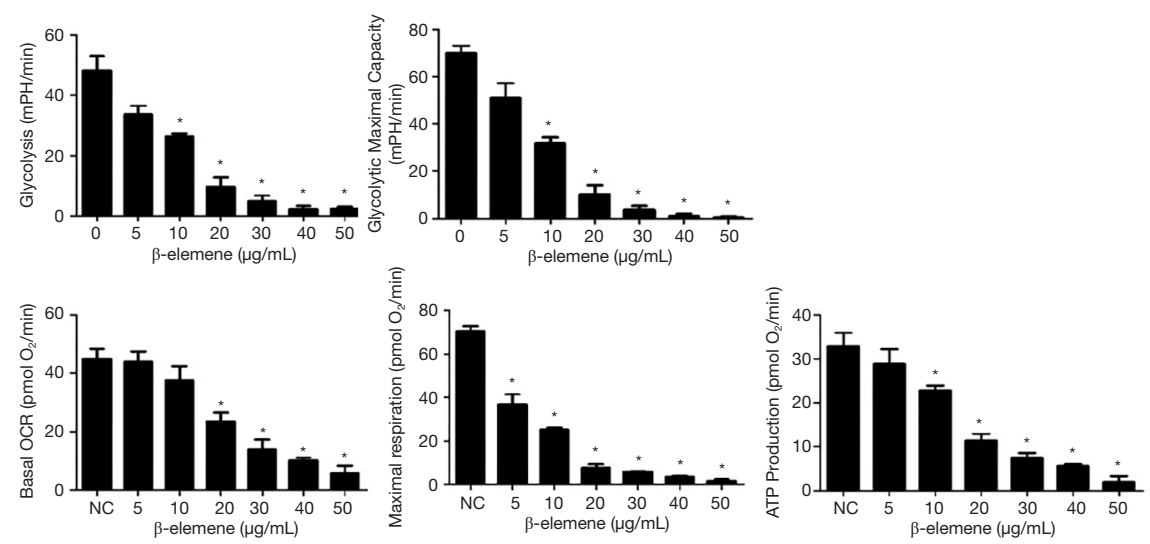

C
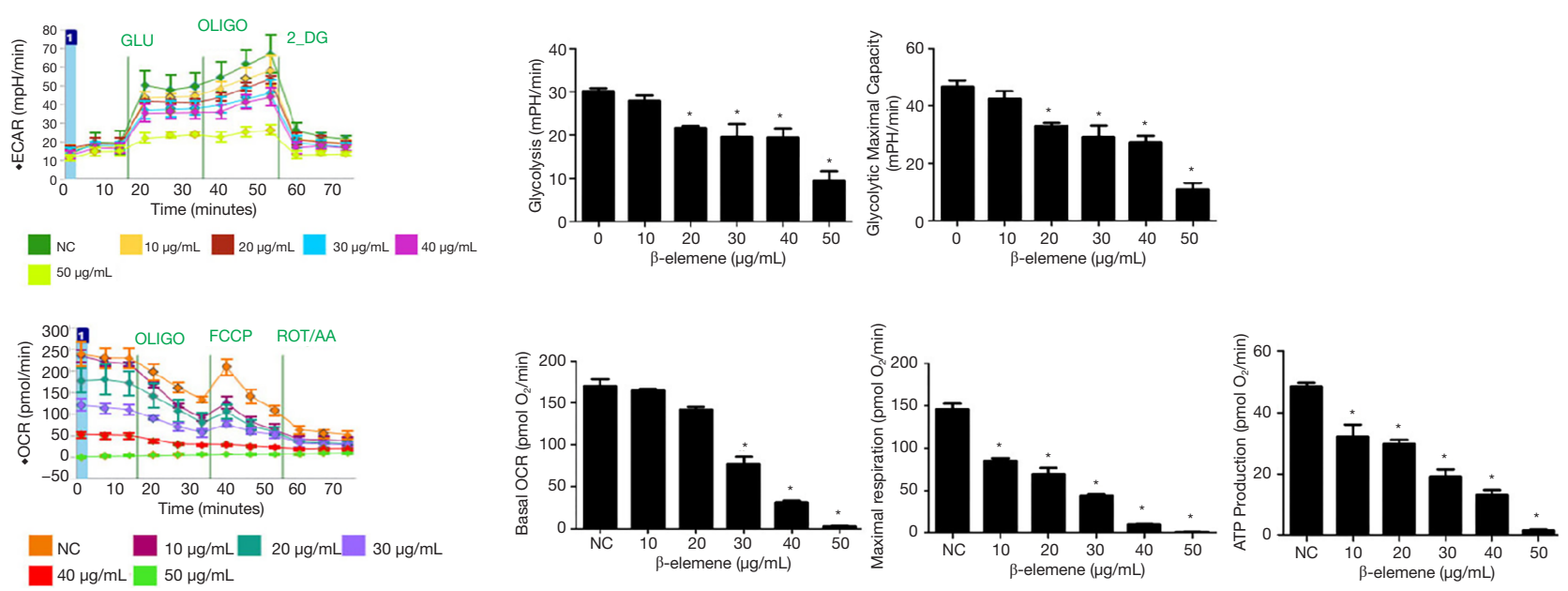

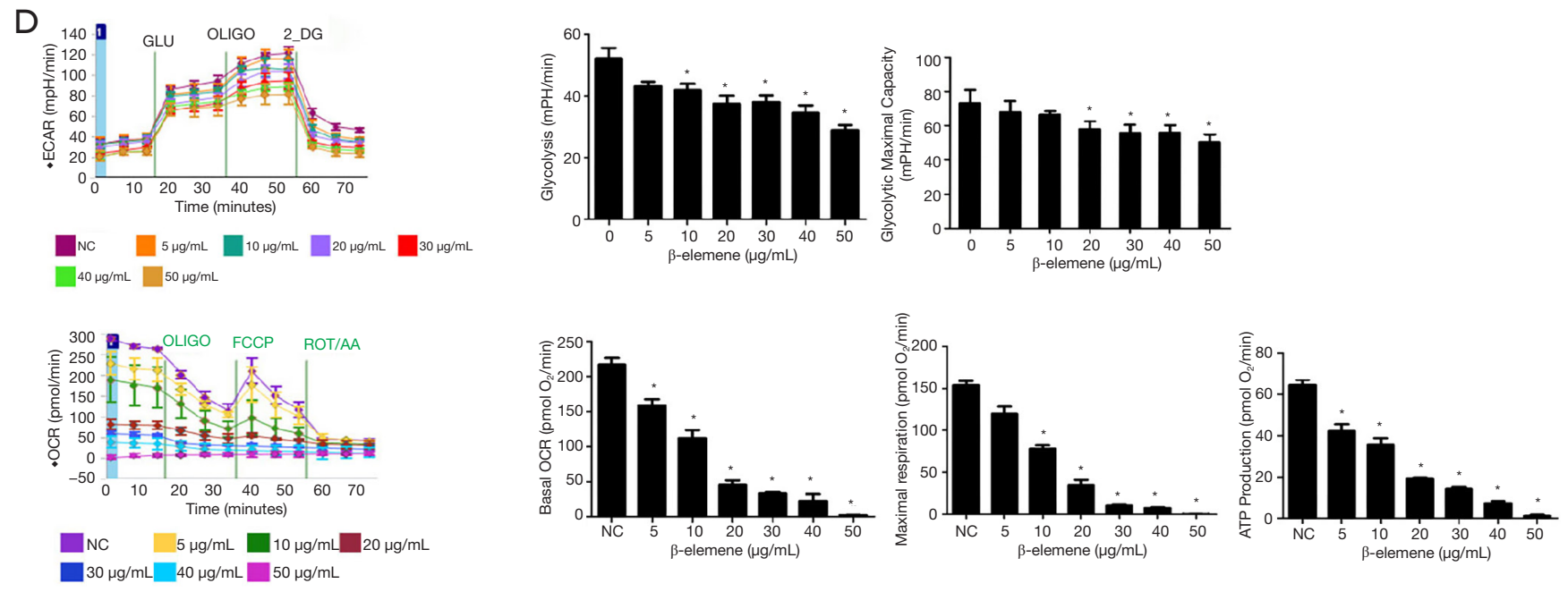

Figure 5 -Elemene changed energy metabolism in DTC cells. $\beta$-Elemene changed the pattern of cellular energy metabolism in IHH-4 (A), TPC-1 (B), K1 (C), and FTC133 (D) manifested as a significant and dose-dependent decrease in glycolysis, maximal glycolytic capacity, basal OCR, maximal respiration, and ATP production. *, compared to control, $\mathrm{P}<0.05$. DTC, differentiated thyroid carcinoma; OCR, oxygen consumption rate.

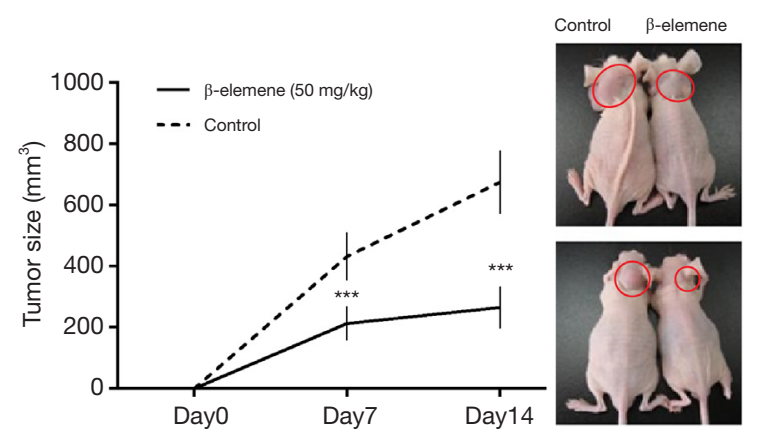

Figure 6 Anti-growth effects of $\beta$-elemene on PTC in a mouse xenograft model. Nude mice were injected subcutaneously with $5 \times 10^{6} \mathrm{IHH}-4$ cells. Ten days later, mice were randomized into two equal groups, and drug treatment was started. After treatment with â-elemene or blank emulsions for 7 and 14 days, tumor volumes in untreated mice were significantly larger than those in drug-treated mice. ***, compared to control, $\mathrm{P}<0.01$. PTC, papillary thyroid carcinoma.

in a dose-dependent manner.

VEGF is an essential regulator of tumor angiogenesis, which is necessary to meet the increased requirement for oxygen and nutrients of rapidly proliferating tumor cells (32). Inhibited angiogenesis is likely to induce tumor dormancy, necrosis, or apoptosis due to insufficient oxygen and nutrients. VEGF is currently considered one of the most crucial factors regulating tumor angiogenesis, suggesting that reducing VEGF expression is vital for DTC treatment. Our results showed that VEGF protein expression was decreased after treatment of IHH4, TPC-1, $\mathrm{K} 1$, and FTC133 cells with different concentrations of $\beta$-elemene, implicating decreased VEGF expression in the mechanism by which $\beta$-elemene inhibits DTC proliferation.

Finally, we used a nude mouse tumor xenograft model to confirm the antitumor effects of $\beta$-elemene in vivo. At 7 and 14 days after treatment with $\beta$-elemene or blank emulsions, tumor volumes in untreated mice were significantly larger than those in drug-treated mice. Our results also showed that $\beta$-elemene treatment significantly decreased the tumor size and weight at all doses, thus confirming the antitumor effects of $\beta$-elemene in vivo.

In conclusion, our study provides the first evidence that $\beta$-elemene has significant inhibitory effects on cell proliferation in human PTC (IHH-4, TPC-1, K1) and FTC (FTC133) cell lines. The antitumor effects include inhibiting cell proliferation, promoting apoptosis, arresting cell cycle progression, inhibiting cell invasion ability, and reducing angiogenesis. We also demonstrated $\beta$-elemene inhibits the respiratory and glycolytic capacity of human DTC cells, which is, therefore, implicated in the mechanism underlying the antitumor effects of $\beta$-elemene. Moreover, $\beta$-elemene inhibited tumor growth in a nude mouse xenograft model. Thus, the evidence obtained in this study 
highlights the potential of $\beta$-elemene as a novel treatment for DTC.

\section{Acknowledgments}

We thank Renee Wang and LetPub Company for linguistic aid during the preparation of this manuscript. We thank Professor Guan from the department of endocrinology and metabolism, and the institute of endocrinology supplied the cell lines, including IHH-4, TPC-1, K1, and FTC133 cells. Funding: This study was supported by grants from the National Natural Science Foundation, China (Grant\# 81370893).

\section{Footnote}

Reporting Checklist: The authors have completed the ARRIVE reporting checklist. Available at http://dx.doi. org/10.21037/atm-20-4460

Data Sharing Statement: Available at http://dx.doi. org/10.21037/atm-20-4460

Conflicts of Interest: All authors have completed the ICMJE uniform disclosure form (available at http://dx.doi. org/10.21037/atm-20-4460). The authors have no conflicts of interest to declare.

Ethical Statement: The authors are accountable for all aspects of the work in ensuring that questions related to the accuracy or integrity of any part of the work are appropriately investigated and resolved. All animal experiments were approved by the Animal Ethics Committee of China Medical University. All procedures were performed following the Guide for the Care and Use of Laboratory Animals and complied with institutional ethical guidelines.

Open Access Statement: This is an Open Access article distributed in accordance with the Creative Commons Attribution-NonCommercial-NoDerivs 4.0 International License (CC BY-NC-ND 4.0), which permits the noncommercial replication and distribution of the article with the strict proviso that no changes or edits are made and the original work is properly cited (including links to both the formal publication through the relevant DOI and the license). See: https://creativecommons.org/licenses/by-nc-nd/4.0/.

\section{References}

1. Lim H, Devesa SS, Sosa JA, et al. Trends in Thyroid Cancer Incidence and Mortality in the United States, 1974-2013. JAMA 2017;317:1338-48.

2. Takano T. Natural history of thyroid cancer [Review]. Endocr J 2017;64:237-44.

3. Durante C, Grani G, Lamartina L, et al. The Diagnosis and Management of Thyroid Nodules: A Review. JAMA 2018;319:914-24.

4. Lubitz CC, Sosa JA. The changing landscape of papillary thyroid cancer: Epidemiology, management, and the implications for patients. Cancer 2016;122:3754-9.

5. Thyroid Cancer Statistics. Available online: http:// seercancergov/statfacts/html/thyrohtml. Accessed June 15, 2016.

6. Chang YW, Kim HS, Kim HY, et al. Should central lymph node dissection be considered for all papillary thyroid microcarcinoma? Asian J Surg 2016;39:197-201.

7. Warburg O. On the origin of cancer cells. Science 1956;123:309-14.

8. Lunt SY, Vander Heiden MG. Aerobic glycolysis: meeting the metabolic requirements of cell proliferation. Annu Rev Cell Dev Biol 2011;27:441-64.

9. Vander Heiden MG, Cantley LC, Thompson CB. Understanding the Warburg effect: the metabolic requirements of cell proliferation. Science 2009;324:1029-33.

10. Coelho RG, Cazarin JM, Cavalcanti de Albuquerque JP, et al. Differential glycolytic profile and Warburg effect in papillary thyroid carcinoma cell lines. Oncol Rep 2016;36:3673-81.

11. Dosoky NS, Setzer WN. Chemical Composition and Biological Activities of Essential Oils of Curcuma Species. Nutrients 2018;10:1196.

12. Long J, Liu Z, Hui L. Anti-tumor effect and mechanistic study of elemene on pancreatic carcinoma. BMC Complement Altern Med 2019;19:133.

13. Pan $Y$, Wang W, Huang S, et al. Beta-elemene inhibits breast cancer metastasis through blocking pyruvate kinase M2 dimerization and nuclear translocation. J Cell Mol Med 2019;23:6846-58.

14. Xu L, Guo T, Qu X, et al. beta-elemene increases the sensitivity of gastric cancer cells to TRAIL by promoting the formation of DISC in lipid rafts. Cell Biol Int 2018;42:1377-85.

15. Guo Z, Liu Z, Yue H, et al. Beta-elemene increases chemosensitivity to 5 -fluorouracil through down- 
regulating microRNA-191 expression in colorectal carcinoma cells. J Cell Biochem 2018;119:7032-9.

16. Zhou J, He LL, Ding XF, et al. Combinatorial Antitumor Effect of Rapamycin and beta-Elemene in Follicular Thyroid Cancer Cells. Biomed Res Int 2016;2016:6723807.

17. Elkin ER, Harris SM, Loch-Caruso R. Trichloroethylene metabolite S-(1,2-dichlorovinyl)-1-cysteine induces lipid peroxidation-associated apoptosis via the intrinsic and extrinsic apoptosis pathways in a first-trimester placental cell line. Toxicol Appl Pharmacol 2018;338:30-42.

18. Rathore R, McCallum JE, Varghese E, et al. Overcoming chemotherapy drug resistance by targeting inhibitors of apoptosis proteins (IAPs). Apoptosis 2017;22:898-919.

19. Davies L, Welch HG. Increasing incidence of thyroid cancer in the United States, 1973-2002. JAMA 2006;295:2164-7.

20. Pilli T, Prasad KV, Jayarama S, et al. Potential utility and limitations of thyroid cancer cell lines as models for studying thyroid cancer. Thyroid 2009;19:1333-42.

21. Khatami F, Larijani B, Nikfar S, et al. Personalized treatment options for thyroid cancer: current perspectives. Pharmgenomics Pers Med 2019;12:235-45.

22. Faubert B, Boily G, Izreig S, et al. AMPK is a negative regulator of the Warburg effect and suppresses tumor growth in vivo. Cell Metab 2013;17:113-24.

23. Patra KC, Wang Q, Bhaskar PT, et al. Hexokinase 2 is required for tumor initiation and maintenance and its systemic deletion is therapeutic in mouse models of cancer. Cancer Cell 2013;24:213-28.

24. Li L, Liang Y, Kang L, et al. Transcriptional Regulation

Cite this article as: Zhao L, Wei J, Wang S, Lang T, Shi X, Shan Z, Teng W. Beta-elemene inhibits differentiated thyroid carcinoma metastasis by reducing cellular proliferation, metabolism and invasion ability. Ann Transl Med 2020;8(19):1232. doi: 10.21037/atm-20-4460 of the Warburg Effect in Cancer by SIX1. Cancer Cell 2018;33:368-85.e7.

25. Xu Q, Tu J, Dou C, et al. HSP90 promotes cell glycolysis, proliferation and inhibits apoptosis by regulating PKM2 abundance via Thr-328 phosphorylation in hepatocellular carcinoma. Mol Cancer 2017;16:178.

26. Graziano F, Ruzzo A, Giacomini E, et al. Glycolysis gene expression analysis and selective metabolic advantage in the clinical progression of colorectal cancer. Pharmacogenomics J 2017;17:258-64.

27. Leemans CR, Snijders PJF, Brakenhoff RH. The molecular landscape of head and neck cancer. Nat Rev Cancer 2018;18:269-82.

28. Adams JM, Cory S. The Bcl-2 protein family: arbiters of cell survival. Science 1998;281:1322-6.

29. Chen D, Zheng X, Kang D, et al. Apoptosis and expression of the Bcl-2 family of proteins and P53 in human pancreatic ductal adenocarcinoma. Med Princ Pract 2012;21:68-73.

30. Wang SL, Yu XJ, Zhao ZK. Haplopappus gracillis Resources of Elemene in China: a Review. Zhongguo Zhong Xi Yi Jie He Za Zhi 2015;35:764-8.

31. Wang TS, Sosa JA. Thyroid surgery for differentiated thyroid cancer - recent advances and future directions. Nat Rev Endocrinol 2018;14:670-83.

32. Chekhonin VP, Shein SA, Korchagina AA, et al. VEGF in tumor progression and targeted therapy. Curr Cancer Drug Targets 2013;13:423-43.

(English Language Editor: J. Chapnick) 